\title{
Influence of fly ash on the pore structure of mortar using a differential scanning calorimetry analysis
}

\author{
Zbigniew Rusin ${ }^{1}$, Piotr Stępien ${ }^{1 *}$ and Karol Skowera ${ }^{1}$ \\ ${ }^{1}$ Kielce University of Technology, Faculty of Civil Engineering and Architecture, Al. Tysiąclecia \\ Państwa Polskiego 7, 25-314 Kielce, Poland
}

\begin{abstract}
In the paper a low-temperature thermoporometry using differential scanning calorimetry (DSC) was employed for analyse of influence of siliceous fly ash (FA) on pore structure of non-air-entrained mortars (pore size, connectivity). A method of interpreting a heat flux differential scanning calorimetry records in pore structure was used for this purpose. The results demonstrated that the: (i) fly ash mortars have virtually no pores inaccessible to water, unlike the mortars with plain Portland cement in which inaccessible pores constitute a significant fraction, growing with the increase in w/b; (ii) with a decrease in $w / b$ the ink-bottle volume decreases. Fraction of this pore type is relatively larger in fly ash mortars; (iii) Siliceous fly ash increased the volume of pores greater than $8 \mathrm{~nm}$, in particular in the group with radii larger than $20 \mathrm{~nm}$ at all w/b ratios.
\end{abstract}

\section{Introduction}

Practical experience and scientific research over the last half-century have provided a wealth of information on the qualitative differentiation of siliceous fly ashes (FA) and their potential for use in concrete technology. Fly ash with finer particles (below $10 \mu \mathrm{m}$ ), less unburnt carbon (coal) and more vitreous phases of increased reactivity improve the properties of blended cements [1]. Increase in FA particle size increases the content of carbon, thereby creating various technological problems. Experience shows that the frost resistant cement matrix with siliceous fly ash can be obtained with adequately low w/b $[2,3]$. In comparison to material containing ordinary Portland cement, fly ash increase the total porosity of hardened cement matrix $[4,5]$. It was found that the addition of fly ash in blended cement after a long curing time reduces the cross-section of capillary pores relative to ordinary Portland cement materials $[6,7,8,9,10,11]$. As a result, permeability is reduced, thereby restricting the flow of water and constituents dissolved in it.

The authors have a similar view to that presented in the literature $[12,13,14]$ that a much more useful tool for assessing the structure of pores in the described cases is thermoporometry (TMP) with use of differential scanning calorimetry (DSC). DSC thermoporometry does not have the disadvantages of the MIP method for example allows

* Corresponding author: pstepien@tu.kielce.pl 
for a better assessment of the size of pore spaces and their interconnections, especially pore structure at the level below $50 \mathrm{~nm}$. In calorimetric tests hysteresis between temperatures of freezing and melting of water has been widely observed $[15,16]$. The observed hysteresis is derived primarily from the geometric characteristics of the pore space. Assuming that the pores have a cylindrical shape, the freezing temperatures of water can be many degrees lower than the melting point of ice confined in pores [17]. In fact, the pores in the hardened cement paste make up a single pore space with a very complex shape. Sun and Scherer analysed these problems [14]. Spheroidal pores whose internal dimensions are smaller than $50 \mathrm{~nm}$ may contain (supercooled water) water that does not crystallize in the spontaneous nucleation phase. The ice then penetrates the inside of the such pores through much smaller pores. This phenomenon can be used to analyse of pore connectivity.

\section{Methodology and scope of study}

This paper reports the influence of siliceous fly ash and w/b ratio on the pore structure in non-air-entrained cement mortars made with CEM I 32,5 and CEM II/B-V 32,5 (fly ash content of 0 and $33 \%$ of the cement mass respectively). The mortars were produced with quartz sand (dried to constant mass at $105^{\circ} \mathrm{C}$ ), plain Portland cement CEM I 32,5R, cement blended with siliceous fly ash CEM II/B-V, and tap water. In mortars with the w/b ratio of 0.37 , a superplasticizer was added at $0.5 \%$ by mass of the binder. The water contained in the admixture was included in the calculation of the w/b ratio. Table 1 summarizes the mixtures.

Table 1. Composition of the mortars expressed per $1 \mathrm{~m}^{3}$.

\begin{tabular}{|c|c|c|c|c|c|c|}
\hline Composition & \multicolumn{3}{|c|}{ CEM I 32,5 } & \multicolumn{3}{c|}{ CEM II/B-V 32,5 } \\
\hline $\mathrm{w} / \mathrm{b}$ & 0.37 & 0.45 & 0.53 & 0.37 & 0.45 & 0.53 \\
\hline Sand, $\mathrm{kg} / \mathrm{m}^{3}$ & 1367 & 1317 & 1254 & 1296 & 1278 & 1229 \\
\hline Cement, $\mathrm{kg} / \mathrm{m}^{3}$ & 683 & 658 & 627 & 648 & 639 & 614 \\
\hline Water $*), \mathrm{kg} / \mathrm{m}^{3}$ & 251 & 296 & 332 & 238 & 288 & 326 \\
\hline $\begin{array}{c}\text { Plasticizer, \% by } \\
\text { mass of cement }\end{array}$ & 0.5 & 0 & 0 & 0.5 & 0 & 0 \\
\hline
\end{tabular}

*) - mass of water minus the mass of water contained in the plasticizer

In order to limit the volume occupied by the air remaining after the mixing process and being a side effect of the addition of the plasticizing admixture, fresh mortars were subjected to vacuum deaeration with simultaneous vibration. The content of air retained after deaeration was examined using the pressure method in accordance with PN EN-1015-7 in the TESTING apparatus with a working volume of $1 \mathrm{dm}^{3}$. Then 100x100x100 mm cubes were formed. After demoulding, the mortars were stored for 7 days in water and then for 80 days (temperature $20 \pm 2{ }^{\circ} \mathrm{C}$, relative air humidity $50 \pm 5 \%$ ). The core specimens for calorimetry $(\varnothing 13.5 \times 70 \mathrm{~mm})$ were drilled from the cubes, dried at $105{ }^{\circ} \mathrm{C}$ and vacuum saturated with distilled water. The heat flow signals during cooling and heating runs were recorded with a differential scanning calorimeter BT2.15CS (SETARAM). The scanning program included cooling the specimen from $+20{ }^{\circ} \mathrm{C}$ to $-80{ }^{\circ} \mathrm{C}$, leaving it to stabilize for 30 minutes at $-80{ }^{\circ} \mathrm{C}$, and heating it to $+20{ }^{\circ} \mathrm{C}$. The scanning speed was $0.09{ }^{\circ} \mathrm{C} / \mathrm{min}$. The mortar density was tested using a LeChatelier flask. The volumetric density was calculated from the ratio of mass of dried specimens to their volume. 


\section{Analysis of the results}

The differences between CEM I and CEM II/B-V mortars are shown in Table 2.

Table 2. Selected mortar properties.

\begin{tabular}{|c|c|c|c|c|c|c|c|}
\hline \multirow{2}{*}{$\begin{array}{c}\text { Cement } \\
\text { type }\end{array}$} & \multirow{2}{*}{ w/b } & $\begin{array}{c}\text { Volume } \\
\text { density }\end{array}$ & $\begin{array}{c}\text { Specific } \\
\text { density }\end{array}$ & Porosity & $\begin{array}{c}\text { Air } \\
\text { content in } \\
\text { the } \\
\text { mixture }\end{array}$ & $\begin{array}{c}\text { Volume } \\
\text { absorpt } \\
\text { ion }\end{array}$ & $\begin{array}{c}\text { Degree to which } \\
\text { the pores are } \\
\text { filled with water }\end{array}$ \\
\cline { 2 - 8 } & $\mathrm{kg} / \mathrm{dm}^{3}$ & $\mathrm{~kg} / \mathrm{dm}^{3}$ & $\%$ & $\%$ & $\%$ & $\%$ \\
\hline \multirow{2}{*}{\begin{tabular}{c}
$\mathbf{3 2 , 5}$ \\
\cline { 2 - 8 }
\end{tabular}} & 0.37 & 2.151 & 2.716 & 20.8 & 2.21 & 17.2 & 83 \\
\cline { 2 - 8 } & 0.45 & 2.117 & 2.720 & 22.2 & 0.93 & 18.0 & 81 \\
\hline \multirow{2}{*}{$\begin{array}{c}\text { CEM } \\
\text { II/B-V } \\
\mathbf{3 2 , 5}\end{array}$} & 0.53 & 2.048 & 2.724 & 24.8 & 0.84 & 19.2 & 77 \\
\cline { 2 - 8 } & 0.45 & 2.025 & 2.598 & 22.1 & 1.11 & 22.1 & 100 \\
\hline
\end{tabular}

The porosity, absorption, degree to which the pores are filled with water are higher in case of CEM II/B-V mortars.

The heating and cooling of the specimens in the DSC experiments produced heat flux diagrams showing the thermal effects of specific heat of water and ice and water-ice-water phase transition. Heat capacity versus temperature plots are shown in Fig. 1. On the basis of the thermal effects that accompany the water phase transition during freezing, it is possible to determine the pore connectivity, while the dimensions of the interior of the pores can be estimated from the analysis of the endothermic part of the plot.
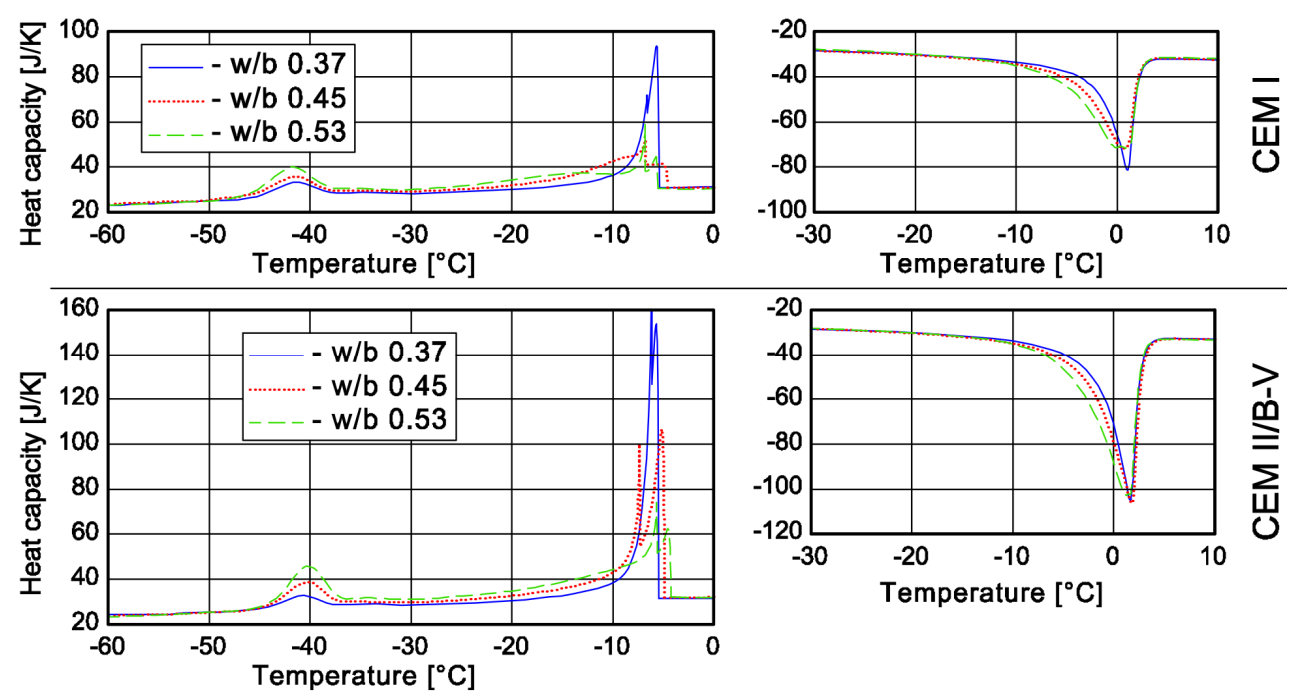

Fig. 1. Heat capacity curves for mortar specimens with ordinary Portland cement and cement containing 33\% siliceous fly ash - cooling and heating phase.

Thermal effects not related to the water phase transition were removed from the heat capacity curves of exothermic and endothermic phases. Calculation of the baseline necessary for this purpose was presented by Stępień in [18]. Calculation of pore size 
distribution based on endothermic effects of the observed phenomena encounters problems in the final heating stage. At that point, melting of relatively large amounts of ice requires the supply of much larger amounts of thermal energy to the specimen, and the temperatures recorded inside the calorimeter and inside the specimen vary significantly. Due to this effect, the assignment of recorded thermal effects to the actual temperatures at which the phase transition occurs is distorted. In order to partially eliminate this phenomenon, a proprietary analytical procedure was used that allows more precise adjustment of specific amounts of energy to the actual temperatures in which the phase transition occured. The algorithm was described thoroughly in [19]. Figure 2 shows original and corrected plots of water phase transition energy during the endothermic stage (heating).

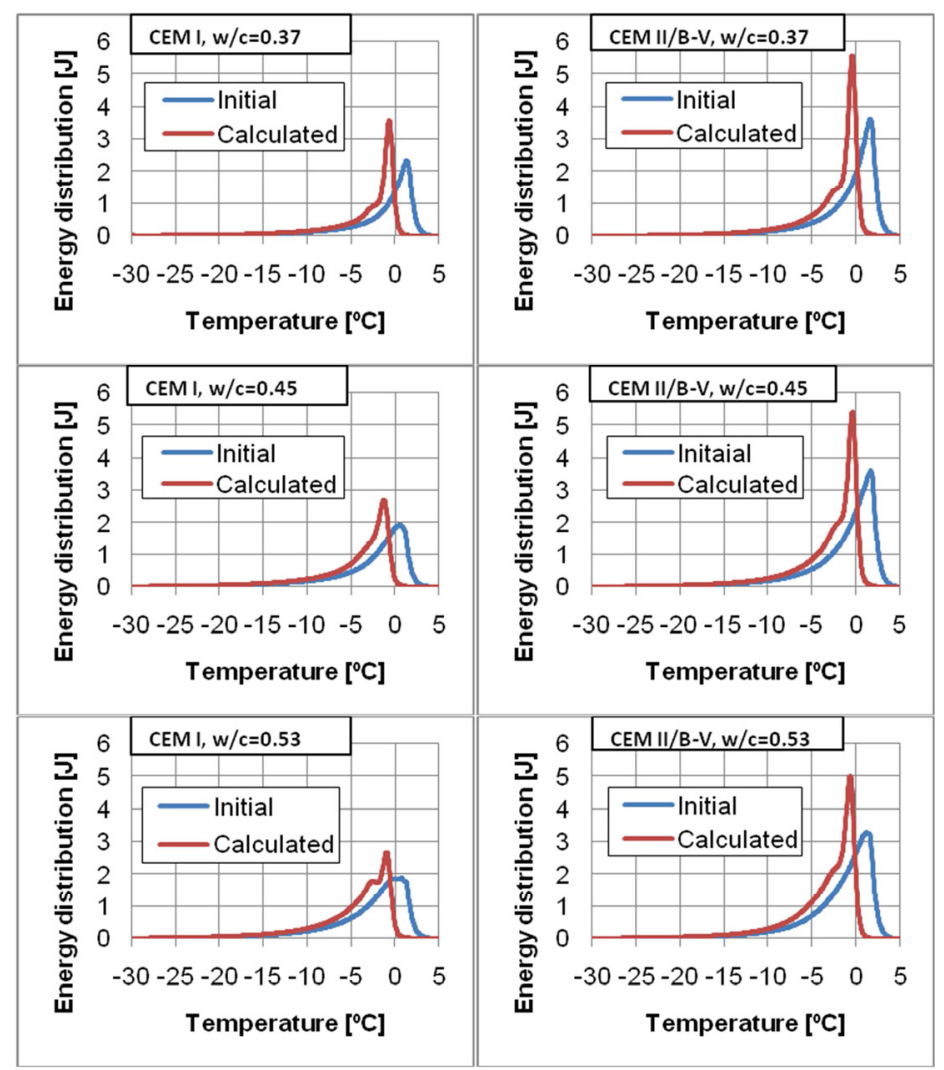

Fig. 2. Phase transition energy in the mortars before correction (initial - red colour) and after correction (calculated - blue colour). 


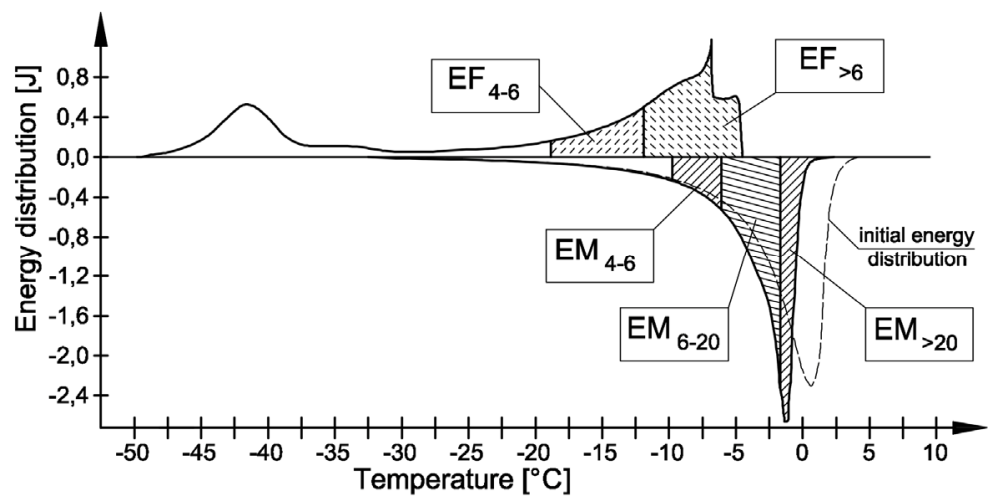

Fig. 3. Division into phase transition intervals, $\mathrm{CEM} I$, w/b=0.45.

In cooling process only analysis relating the thermal phenomena to specific dimensions of pores is possible after the stabilization of phase transition of supercooled water and relatively balanced course of phase transition are achieved. It was assumed that stabilization occurred at a temperature of about $-12{ }^{\circ} \mathrm{C}$, which corresponded to a pore radius of about $6 \mathrm{~nm}$, according equation (1). The energy distribution at freezing below this temperature was analysed without applying any special corrections. Phase transition energy for freezing process was assigned to three ranges of radius values: less than $4 \mathrm{~nm}, 4$ to $6 \mathrm{~nm}$ and more than $6 \mathrm{~nm}$. The energy values were added up in each interval respectively $E F<4, E F 4-6$, EF>6 (fig. 3). An analogous procedure was performed for the corrected phase transition energy plot at heating. The limit values in the ranges corresponded to ice melting in pores with a radius of 4, 6, $20 \mathrm{~nm}$, corresponding respectively EM4-6, EM6-20, EM>20 (fig. 3). For the freezing process, equation (1) was used, whereas for the melting process, equation (2) was used [17]:

$$
\begin{aligned}
& r_{\mathrm{p}}=-(64.67 / \Delta T)+0.57 \\
& r_{\mathrm{p}}=-(32.33 / \Delta T)+0.68
\end{aligned}
$$

where $\Delta \mathrm{T}=\mathrm{T}-\mathrm{T}_{0}, \mathrm{~T}-$ phase transition temperature, $\mathrm{T}_{0}-0{ }^{\circ} \mathrm{C}$

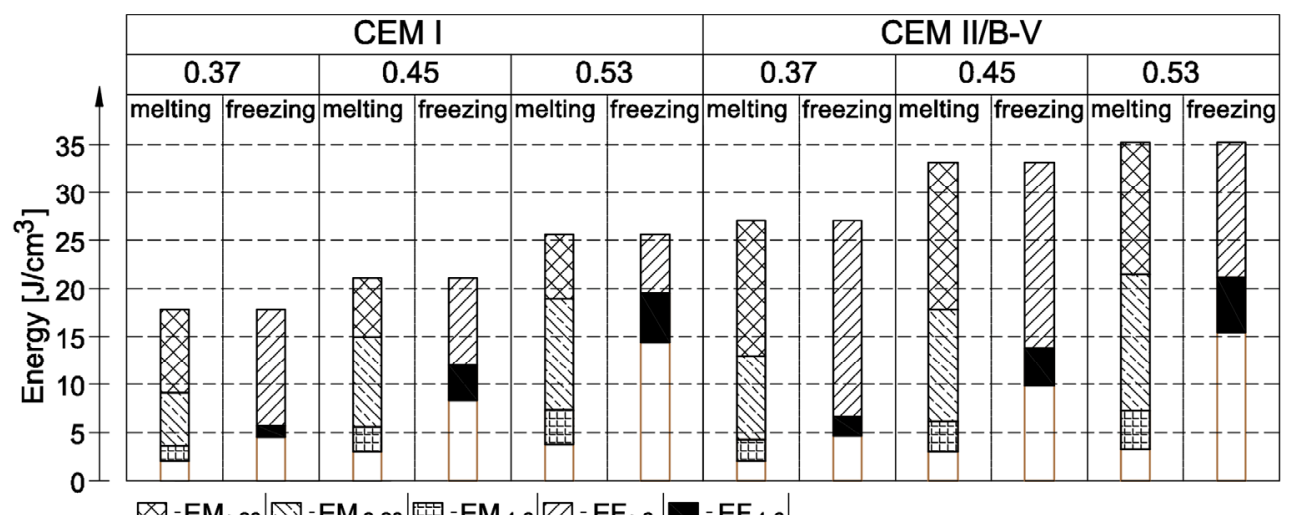

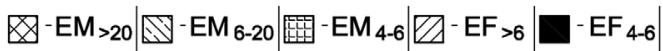

Fig. 4. Energy values in particular intervals expressed per $1 \mathrm{~cm}^{3}$ of the mortar based on plain Portland cement and mortar containing $33 \%$ siliceous fly ash by cement mass. 
A general observation is the fact that the recorded amount of energy corresponding to the phase transitions of water at freezing in the pores with radii greater than $4 \mathrm{~nm}$ decreases with increasing $w / b$. The size of this peak increases with the increasing $w / b$ ratio (exothermic peak in the figure 1). The increase in the volume of ink-bottle pores having $r_{p}<25 \mathrm{~nm}$ with the increase in $w / b$ is probably the cause of this effect. The connections of these pores with the general pore space occur through the pores with radii well below $6 \mathrm{~nm}$. From Fig. 1, it follows that most of these connections were of much smaller dimensions, with radii within 1.8 to $2.3 \mathrm{~nm}$ and water freezing temperature below $-37{ }^{\circ} \mathrm{C}$. Based on the observed difference in energy values in the exothermic and endothermic phases, it can easily be inferred that the relative volume of ink-bottle pores decreases with a decrease in $\mathrm{w} / \mathrm{b}$.

For the studied mortars, thermal effects associated with phase transition were not observed in the temperature range $-52{ }^{\circ} \mathrm{C}$ to $-80{ }^{\circ} \mathrm{C}$. According to the equation by Brun et al. [17], $-52{ }^{\circ} \mathrm{C}$ corresponds to the freezing of water inside cylindrical pores with a radius of approximately $1.8 \mathrm{~nm}$. To calculate the volume of pores in which ice melts at a given temperature, the phase transition heat $\mathrm{L}(\mathrm{T})(3)$ and the ice density $\rho_{\text {ice }}$ (4) must be known. In this paper the values given by Sun and Scherer [18] were taken for the calculations. The geometric characteristics of the pore space occupied by ice was determined by thermometric analysis using a proprietary algorithm to analyse the distribution of phase transition energy in individual temperature ranges. For the analysis of pore volume distribution, the volume of pores inaccessible to water during vacuum saturation was calculated from the difference between total porosity and absorption. Another assumption was that pores with radii from about 1.5 to $1.8 \mathrm{~nm}$ contain strongly adsorbed water that is incapable of crystallization at temperatures up to $-80{ }^{\circ} \mathrm{C}$ (no energy accompanying phase transition was recorded below $-52{ }^{\circ} \mathrm{C}$ ). The size distributions of frozen water-containing pores with the radius above $1.8 \mathrm{~nm}$ were determined, including the air voids formed in the mixture after compaction. The pore dimensions were arbitrarily classified in 10 ranges. The respective diagrams are shown in Fig. 5. 


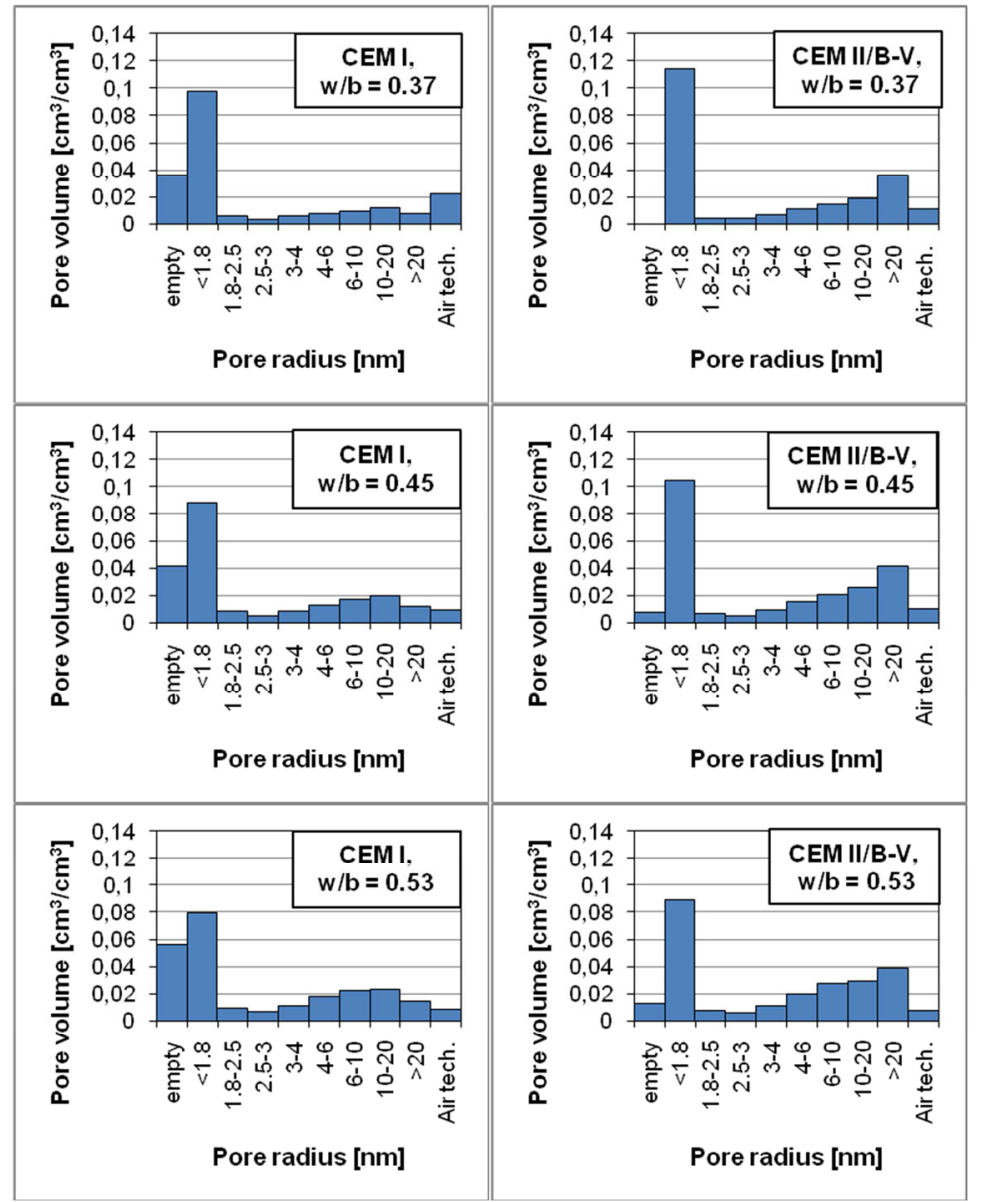

Fig. 5. Pore size distribution in the mortars.

According to Figure 5, the addition of siliceous fly ash causes the disappearance of pores that do not fill with water during vacuum saturation. Their volume in CEM I mortars is significant and increases with the $\mathrm{w} / \mathrm{b}$ increase. The reverse phenomenon applies to pores with $r_{p}<1.8 \mathrm{~nm}$, containing adsorbed water, unable to crystallize at temperatures down to $-80{ }^{\circ} \mathrm{C}$. There are more of them in CEM II/B-V mortar for each w/b value. The sum of the volumes of both of these pore groups is greater in CEM I. Analysis of Fig. 5 shows that the siliceous fly ash in the binder causes a noticeable increase in the volume of pores with a radius $r_{p}>4 \mathrm{~nm}$. The most significant change occurs in the group of pores with a radius greater than $20 \mathrm{~nm}$ (without taking into account the air voids), where almost three-fold increase in their volume is observed. Water freezes in them at temperatures up to $-18{ }^{\circ} \mathrm{C}$. On this basis, it can be concluded that they constitute a coherent hydraulic system in which the connecting pores have radii greater than $4 \mathrm{~nm}$, in which the pore blocking effect associated with the ink-bottle pores does not occur. 


\section{Conclusions}

Conclusions regarding the effects of fly ash on the pore space of the examined mortars are as follows:

- The addition of fly ash as a 33\% Portland cement supplement resulted in an increase in the overall porosity in the investigated mortars.

- The degree of filling the pores with water (at vacuum saturation) in fly ash mortars was $95 \%$ to $100 \%$, while in the mortars with plain Portland cement, it was $77 \%$ to $83 \%$ - in both cases these values decreased with an w/b increase.

- Fly ash mortars had virtually no pores inaccessible to water, unlike the mortars with plain Portland cement in which inaccessible pores constitute a significant fraction.

- Fly ash mortars contained relatively more pores with non-freezable water at temperatures up to $-80{ }^{\circ} \mathrm{C}$.

- Siliceous fly ash increased the volume of capillary pores, in particular in the group with radii greater than $20 \mathrm{~nm}$ at all $\mathrm{w} / \mathrm{b}$ ratios.

- The ink-bottle pore volume decreased in both mortar types with a decrease in $\mathrm{w} / \mathrm{b}$ - the fraction of this pore type is relatively larger in fly ash mortars.

\section{References}

1. A. M. Neville, Properties of concrete, CMA (2011)

2. V. M. Malhorta, Cem. Concr. Compos. 12, 271-277 (1990)

3. N. Bouzoubaa, B. Fournier, V. M. Malhorta, D. M. Golden, Mater. J. 99, 560-567 (2002)

4. J. Yang, Y. Su, X. He, H. Tan, Y. Jiang, L. Zeng, B. Strnadel, Fuel Proc. Tech. 181, 75-90 (2018)

5. Z. Yu, G. Ye, Con. and Build. Mat. 45, 30-35 (2013)

6. J. Wawrzeńczyk, T. Juszczak, A. Molendowska, , Proc. Eng. 161, 73-78 (2016)

7. M. R. Nokken, Por. Cem. Assos. R\&D, 2861 (2004)

8. Z. Yu, J. Ma, G. Ye, K. van Breugel, X. Shen, Con. and Build. Mat. 144, 493-501 (2017)

9. Z. Yu, C. Ni, M. Tang, X. Shen, Con. and Build. Mat. 175, 458-466 (2018)

10. J. D. Bapat, Adv. in Cem. Res. 13, 139-155 (2001)

11. M. S. Meddah, A. Tagnit-Hamon, ACI Mat. J. 106 (3), 241-250 (2009)

12. M. Wu, K. Fridh, B. Johannesson, M. R. Geiker, Ther. Acta 665, 11-19 (2018)

13. K. Kurumisawa, Con. and Build. Mat. 101, 926-931 (2015)

14. Z. Sun, G.W. Scherer, Cem. and Con. Res. 40, 740-751 (2010)

15. D. H. Bager, E.J. Sellevold, Cem. and Con. Res. 16, 709-720 (1986)

16. K. A. Snyder, D.P. Bentz, Cem. and Con. Res. 34, 2045-2056 (2004)

17. M. Brun, A. Lallemand, J. F. Quinson, C. Eyraud, Ther. Acta 21, 59-88 (1977)

18. P. Stępień, Relationship between water-ice-water phase transitions with pore space characteristics in stone materials, (Kielce 2018) (In Polish)

19. P. Stępień, Z. Rusin, K. Skowera, Materials 13, 1-17 (2020) 